\title{
Hodgkin Lenfoma Nüks ve/veya Kemoterapi Dirençli Olgularda Hematopoetik Kök Hücre Nakli ve Yüksek Doz Kemoterapi: Tek Merkez Deneyimi
}

\section{Hematopoietic Stem Cell Transplantation and High Dose Chemotherapy in Recurrent and/or Chemotherapy Resistant Hodgkin Lymphoma Cases: A Single Center Experience}

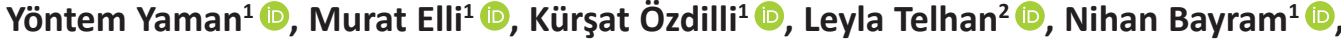 \\ Volkan Hazar $^{3}$ (D), Ebru Tuğrul Sarıbeyoğlu“ ${ }^{4}$, Şifa Şahin ${ }^{5}$ (D), Semak Anak ${ }^{1}$ (i)
}

\author{
${ }^{1}$ istanbul Medipol Üniversitesi, Tıp Fakültesi, Çocuk Hematoloji Onkoloji Bilim Dalı, İstanbul, Türkiye \\ ${ }^{2}$ Istanbul Medipol Üniversitesi Tıp Fakültesi Çocuk Yoğun Bakım Bilim Dalı, i̇stanbul, Türkiye \\ ${ }^{3}$ Medstar Antalya Hastanesi, Antalya, Türkiye \\ ${ }^{4}$ Hospital Carl-Thiem-Klinikum Cottbus, Cottbus, Germany \\ ${ }^{5}$ İstanbul Üniversitesi Tıp Fakültesi Çocuk Hematoloji Onkoloji Bilim Dalı, İstanbul, Türkiye
}

ORCID ID: Y.Y. 0000-0002-9710-8653; M.E. 0000-0002-0476-5452; K.Ö. 0000-0002-7129-5024; L.T. 0000-0003-0037-7636; N.B. 0000-0002-9688-5223; V.H. 0000-0002-1407-2334; E.T.S. 0000-0003-3294-5394; ş.S. 0000-0001-7402-8944; S.A. 0000-0001-8489-7449

Attf/Citation: Yaman Y, Elli M, Ozdilli K, Telhan L, Bayram N, Hazar V, et al. Hodgkin lenfoma nüks ve/veya kemoterapi dirençli olgularda hematopoetik kök hücre nakli ve yüksek doz kemoterapi: tek merkez deneyimi. Çocuk Dergisi - Journal of Child 2021;21(1):7-12. https://doi.org/10.26650/jchild.2021.1.844098

öz

Giriş: Standart tedavi alan Hodgkin Lymphoma (HL) hastalarının yaklaşık \%20'sinde hastalık dirençli seyredebilir veya tekrar edebilir. Tekrar eden/ dirençli HL'da standart tedavi yüksek doz kemoterapi ve takip eden otolog kök hücre naklidir (OKHN). Otolog KHN sonrası tekrar eden hastalarda ise allojeneik kök hücre nakli (AKHN) önemli bir kurtarma tedavisi olarak görülmektedir.

Amaç: Medipol Üniversitesi Tıp Fakültesi çocuk kemik iliği nakil ünitesinde OKHN ve AKHN yapılan hastalarda sonuçları değerlendirmek.

Yöntem: Tekrar eden/dirençli HL nedeniyle 2014 Kasım ile Temmuz 2019 tarihleri arasında merkezimizde OKHN yapılan 18 olgu retrospektif olarak değerlendirilmiştir. Otolog KHN sonrası hastalığı tekrar eden ve AKHN yapılan hastalarda ayrıca değerlendirilmiştir.

Bulgular: Onaltı hasta halen hayattadır. Onbir hastada OKHN sonrası hastalık tekrar etmiştir. Relaps eden hastalardan 10'una AKHN yapılmıştır. Bu hastalardan üçünde tekrar görülmüş olup, sekizi nakil sonrası hayattadırlar.

Anahtar Kelimeler: Brentuksimab vedotin, kontrol noktası inhibitörü, kök hücre nakli, relaps, yüksek doz kemoterapi Hodgkin Lenfoma

\section{ABSTRACT}

Background: Nearly $20 \%$ of patients with Hodgkin Lymphoma (HL) who receive standard treatment will relapse or have a refractory disease. Standard treatment for the Relapsed/Refractory (RR) HL is salvage high dose chemotherapy followed by autologous stem cell transplantation (AuSCT). Management of RR HL after AuSCT with allogeneic stem cell transplantation (ASCT) is also considered as an important salvage therapy. Objective: To describe the outcome in pediatric patients with RR HL who underwent AuHSCT and ASCT in Medipol University hematopoietic stem cell transplantation center.

Method: We retrospectively evaluated 18 pediatric patients with RR HL who underwent AHSCT between November 2014 and July 2019. The evaluation of ASCT after RR HL AuSCT is also done.

Results: Sixteen patients are still alive. Eleven of them relapsed after AuHSCT. AllogeneicHSCT was performed on 10 patients who relapsed. Relapse was seen in three patients after AHSCT. Eight of them are still alive.

Keywords: Brentuximab vedotin, check point inhibitör, high dose chemotherapy, Hodgkin Lymphoma, stem cell, relapse, transplantation

Sorumlu Yazar/Corresponding Author: Yöntem Yaman E-mail: yontemyaman@gmail.com

Başvuru/Submitted: 23.12.2020 • Revizyon Talebi/Revision Requested: 10.03.2021 • Son Revizyon/Last Revision Received: $16.03 .2021 \bullet$ Kabul/Accepted: 03.04.2021 


\section{GíRiş}

Son yıllarda Hodgkin lenfoma (HL) tedavisinde hatırı sayılır bir başarıya ulaşılmıştır. Günümüzde radyoterapi ve/veya antrasiklin, alkilleyiciler gibi ilaçların istenmeyen ikincil yan etkilerini mümkün olduğunca ortadan kaldırmaya yönelik risk gruplamaları ve risk gruplarına yönelik azaltılmış tedavileri içeren çalışmalar yapılmaktadır. Ancak halen hastalığı tekrar etmiş (özelikle ilk yıl içinde) ve tedaviye dirençli hastalar önemli bir sorundur. Bu çalışmada hastalık tekrarı ve/veya dirençli hastalık nedeniyle otolog hematopoetik kök hücre nakli (OKHN) ve /veya allojenik hematopoetik kök hücre nakli (AKHN) yapılan hastaların geriye dönük incelemesi yapıldı. Hastaların yüksek doz tedavi gereksinimleri, nüks/dirençli hastalık tedavileri, tedaviye cevapları ve sağ kalım özellikleri araştırıldı.

\section{HASTALAR VE YÖNTEM}

Kasım 2014 ile Temmuz 2019 tarihleri arasında İstanbul Medipol Üniversitesi Hastanesi Çocuk Hematoloji-Onkoloji bilim dalı tarafindan $\mathrm{HL}$ tanısıyla izlenen ve çocuk kemik iliği nakil ünitesinde relaps ve/veya refrakter hastalık nedeniyle OKHN yapılan 18 hastanın geriye dönük incelemesi yapıldı. Otolog KHN sonrası relaps eden ve AKHN yapılan 10 hastanın da geriye dönük incelemesi aynı şekilde yapıldı. Hastaların yüksek doz tedavi gereksinimleri, nüks/dirençli hastalık tedavileri, tedaviye cevapları ve sağ kalım özelikleri araştırıldı. Hastaların verileri hastanenin merkezi kayıt sisteminden ve bilim dalı arşivinden elde edildi. Araştırma öncesinde İstanbul Medipol Üniversitesi Etik Kurulu'ndan onay alındı.

\section{İstatistiksel İncelemeler}

İstatistiksel analizler için Windows ortamında SPSS 17,0 programı kullanıldı. Anlamlılık $p<0,05$ düzeyinde kabul edildi.

\section{SONUÇLAR}

Relaps ve/veya refrakter hastalık edeniyle OKHN ve /veya AKHN yapılan 18 hasta çalışmaya alındı. Hastaların 9'u erkek; 9'u kız idi. Hastaların primer tanı yaşı ortanca 12,69 yıldı (4,56-17,69 yıl).

Hastaların ilk tanı sırasında 3'ü evre II (\%17), 7'si evre III (\%39), ve 8 'i evre IV (\%44) idi. Hastaların 12'sinde (\%67) B semptomları (ateş, kilo kaybı, gece terlemesi) vardı.

Hastaların primer hastalık tedavileri için sıklıkla Adriamisin, bleomisin, vinblastin, dacarbazin , siklofosfamid, vincristin, procarbazin, prednizolon (ABVD-COPP) kombinasyonu kullanılmışt. 18 hastanın 15 'i primer tedavi sırasında radyoterapi almışt.
Onsekiz hastadan 10'una (\%55) dirençli hastalık, 8'ine (\%45) relaps hastalık nedeniyle OKHN yapılmışt. Otolog KHN yapılan 18 hastanın 16 'sında kök hücre kaynağı olarak periferik kök hücre ikisinde ise kemik iliği kullanılmışt. Nakil öncesi hazırıı rejiminde 16 hastada BCNU, etoposid, ARA-C, melfalan; 2 hastada ise bendamustin, etoposid, ARA-C, melfalan kullanıldı. Yüksek doz kemoterapi öncesinde 18 hastanın 5'inde (\%28) iyi parsiyel remisyon sağlanmışt 12 hasta 2 . tam remisyon ve bir hastada da 3. tam remisyonda iken OKHN yapıldı.

Otolog KHN sonrası yapılan değerlendirmede 1 hasta dışında hastaların tamamı tam remisyonda idi. Otolog KHN sonrası izlemde 11 hastada (\%61) ortanca 8,5 ay, ortalama 10,55 $\pm 9,7$ ayda (2,2-35.5 ay) hastalık tekrarı gelişti. Otolog KHN ile ilişkili olarak ağır bir komplikasyon gelişmedi ve hiçbir hasta kaybedilmedi. Relaps saptanan hastaların relapssız hastalara göre tanı yaşı, tanı evresi, B semptomu varlığı, nakil öncesi kalınt hastalık varlığı ve izlem süreleri arasında fark saptanmadı.

Otolog KHN sonrası nüks saptanan 5 hasta sadece brentixumab/vedotin ve bendamustin içeren relaps rejimleri, 2 hasta sadece ICE kemoterapi rejimi almışt; 4 hasta ICE ve brentixumab/ vedotin ile bendamustin içeren relaps rejimini ardışık olarak kullanmışlardı. Otolog KHN sonrası relaps gelişen 11 hastadan 5 'ine tam uyumlu kardeşten (MSD), 3'üne tam uyumlu akraba dışı vericiden (MUD) ve 2 'sine de anneden haploidantik nakil yapıldı. 1 hasta kendisini hastanemize gönderen merkezin isteğiyle AKHN koluna sokulmadı. Haploidantik nakil sonrası remisyona giren fakat engrafman gelişmeyen hastaya aynı donörden ikinci bir nakil daha yapıldı.

Allojenik nakil yapılan 2 hastaya busulfan ve fludarabin ile myeloablatif rejim verildi. 2 hastaya fludarabin, siklofosfamid, 2 hastaya busulfan fludarabin ve 4 hastaya fludara melfalan olmak üzere 8 hastaya yoğunluğu azaltılmış hazırlama rejim (RIC) verildi. Allojeneik KHN yapılan hastaların nakledilen CD34+ hücre sayıları, nötrofil ve trombosit engrafman günleri ve izlem süreleri tabloda verilmiştir (Tablo 1) .

Otolog KHN sonrası tam remisyon sağlanmayan bir hasta AKHN'den 6 ay sonra progresif hastalık nedeniyle kaybedildi. Allojeneik KHN sonrası tam remisyonda olan bir hasta ise nakil sonrası aplazi girdi ve ikinci nakillede aplaziden çıkamayan hasta 6 ayda kaybedildi. Her iki hastada tanı anında Evre IVB idi. Bir hastada AKHN sonrası 1. yılda nüks gelişti. 12 kür Brentixumab/vedotin ve bendamustin ardından nivolumab ile 6 yıl 4 aydır remisyondadır. Bir diğer hastada allojeneik nakil sonrası 8. ayda gelişen nüks sonrası Brentixumab/vedotin ve

Tablo 1: Allojenik kemik iliği nakli yapılan hastaların nakledilen CD34+ hücre sayıları, nötrofil ve trombosit engrafman günleri ve izlem süreleri.

\begin{tabular}{|c|c|c|c|c|}
\hline & En küçük & En büyük & Ortanca & Ortalama \\
\hline CD34+ cell/kg x10 6 & 1,7 & 20,9 & 5,41 & 6,77 \\
\hline Nötrofil engratmanı-gün & 9 & 31 & 12 & 13 \\
\hline Trombosit engraftmanı-gün & 11 & 45 & 17 & 23 \\
\hline İzlem süresi-ay & 6,1 & 76,1 & 61,7 & 53,6 \\
\hline
\end{tabular}


bendamustin ardından nivolumab ile 3 yıl 2 aydır remisyonda izlenmektedir. Allojeneik KHN yapılan diğer 6 hasta ise nakil sonrası 2 yıl ile 5 yıl arasında takip sürelerine sahiptirler ve remisyondadırlar.

Allojenik KHN yapılan hastalar için genel bir değerlendirme yapılırsa relapssız sağ kalım \%60 iken uzun dönem sağkalım $\% 80$ 'dir.

\section{TARTIŞMA}

Hodgkin lenfoma yüksek başarıyla tedavi edilebilir çocukluk çağı kanserlerden biridir; kemoterapi (KT) ve radyoterapi (RT) ile tedaviden sonra uzun süreli sağkalım oranları \%90'ı aşmaktadır. Son otuz yılda, tedavi ilişkili komplikasyonların ve ikincil kanserlerin azaltılması amacıyla RT'nin azaltılması veya tedaviden kaldırılması ve kemoterapinin azaltılması yoluyla yanıt bazlı tedaviye uyumun ve toksisitenin yönetimi amaçlanmıştır. Kombine (RT+KT) yaklaşımlarıyla \%90'a yaklaşan olaysız sağkaIım (EFS) oranları ile yüksek yanıt oranları sağlamasına rağmen, çocukluk çağı HL'de hayatta kalanlarda radyasyona bağlı ikincil kanserler, kardiyovasküler hastalıklar ve tiroid fonksiyon bozukları riski yaşam boyu artmış olarak saptanır (1-6).

Klasik HL hastalarının pek çoğunda birinci basamak tedavi ile kür sağlanır. Ancak risk gruplarına göre düzenlenmiş tedavilere ve kemoradyoterapi kombinasyonlarındaki ilerlemelere rağmen hastaların önemli bir kısmı (özellikle ileri klasik HL (cHL) hastaları) nüks edebilir veya birincil tedaviye direnç gösterebilir $(7,8)$. Primer dirençli hastalığı olan hastalar (yani tedavinin sonunda remisyon elde edilmeyenler) ve primer tedaviden 1 yıldan daha kısa sürede tekrarlayan hastalar daha kötü bir prognoza sahiptir (9). Kurtarma tedavisine iyi yanıt veren hastalarda yüksek doz kombinasyon kemoterapisini takiben OKHN uzun dönemde iyi sonuçlar verdiği gösterilmiştir ve nükseden cHL hastalarının yaklaşık \%50'sinde kür sağlandığı bildirilmiştir (10). Bizim olgu serimizde OKHN yapılan18 hastanın 11 'inde (\%61) nakilden ortanca 10,5 ay $(2,2-35,5$ ay) relaps hastalık geliştiği görüldü. 18 hastanın 10'u dirençli hastalık ve 4'ü erken relaps olgulardı. Otolog KHN sonrası relaps saptanan olguların hepsi erken relaps ve/veya dirençli hastalıkt. Bu durum merkezimize başka merkezlerden refere edilen hastaların ileri evre olmasından kaynaklanıyordu.

Kurtarma kemoterapisine cevap vermeyen (kemoterapi dirençli) nükseden $\mathrm{HL}$ hastalarının sonuçları çok daha kötüdür. Bu grup hastalar için günümüzde antikor-ilaç konjugatları veya immünoterapi gibi yeni yaklaşımlar umut vericidir (11). Allojenik KHN, 'greft versus lenfoma etkisi' yoluyla uzun dönem hastalık kontrolü sağlayabilir. Son yıllara kadar uygun donörlerin olmaması ve peri-transplant döneminde akut morbidite ve mortalite nedeniyle uygulanma sınırlıydı (12). Allojenik KHN, nüks /refrakter HL'de küratif olabilir, ancak HLA-haploidentik AKHN gibi alternatif donör kaynaklarında bile nüks oranlarının \% 40'a ulaşan oranlarda yüksek olduğu bildirilmiştir (13). Bizim olgu serimizde allojenik nakil yapılan 10 hastadan sadece ikisinde nüks hastalık gelişti, bu hastalar da BV/bendamustin ve nivolumab ile remisyonda izlemdedir.
Daha düşük dozlarda kemo-radyoterapi içeren miyeloablatif olmayan veya RIC rejimleri ile AKHN sonrası mortalite ve morbidite azaltıldığı gibi, lenfomayla savaşta greftin immünolojik özelliklerine güvenilmektedir $(14,15)$. Avrupa grubu tarafindan yapılan bir retrospektif bir çalışmada miyeloablafif gruba kıyasla, RIC rejim alan hastalarda AKHN ile tedavi edilen hastalarda hem relapssız mortalite hem de genel sağ kalım daha iyi bulunmuştur (16). Nakil sonrası siklofosfamid kullanan modern immünosüpresif rejimler, haploidantik AKHN yapılan hastalarda Graft-host hastalığı (GVHH) sıklığını etkili bir şekilde azaltmıştır. Relaps / refrakter HL'li 90 hasta için RIC AKHN'nin çok merkezli bir retrospektif incelemesinde, HLA uyumlu akraba $(n=38)$, akraba dışı $(n=24)$ veya HLA-haploidentik ilişkili $(n=28)$ donörlerin sonuçlarını karşılaştrılan bir çalışmada iki yıllık OS, PFS sırasıyla \%53, \%23 (HLA uygun akraba), \%58, \%29 (HLA uygun akraba dışı) ve $\% 58, \% 51$ (haploidentik) idi. Haploidentik nakil yapılan alıcılarda nüks riski diğer iki gruba göre daha düşüktü saptanmıştır. Ayrıca bu hastalarda akut ve kronik GVHH sıklığının artmadığı bildirilmiştir (17).

Platin bazlı ve ifosfamid içeren kemoterapiler, relaps yada primer refrakter hastalar için standart rejimlerdir. Ifosfamid, karboplatin, etoposid içeren (ICE) rejimler ile DHAP (deksametazon, sitarabin, sisplatin), IGeV (ifosfamid, gemsitabin, vinorelbin) ve GDP (gemsitabin, deksametazon, sisplatin) rejimleri en yaygın kullanılan kombinasyonlardır. Tüm bu rejimler, genel yanıt oranları (ORR) \%70 ila \%90 arasında değişmektedir, ancak tam yanıt (CR) oranları daha düşük ve $\% 20$ ila $\% 75$ arasında çok daha değişkendir (18-24). Bizim olgu serimizde relaps/refrakter hastalık nedeniyle 18 hastadan 8'sine; otolog KHN sonrası nüks saptanan 11 hastadan 6'sına ICE rejimi verilmişti.

Brentuksimab vedotinin kurtarma tedavisi için ilk tercih, tekli tedavi seçeneği olarak bildiren çalışmalarda: hastaların bir kısmı kısa bir BV tedavisi ile PET-negatif duruma ulaşabilir ve miyelotoksik kemoterapiden kaçınabilir olarak bildirilmiştir. CR ulaşılamayan hastalarda konvansiyonel kemoterapi seçenekleri ile başarı sağlanabileceği, uzun dönem sonuçlarında sadece BV ile CR elde eden hastalar ile ileri kemoterapiden sonra CR elde eden hastalar arasında önemli bir fark olmadığı da belirtilmiştir. Otolog KHN mobilizasyonunu bozmadan, ilk kurtarma tedavisi için BV etkili ve güvenli bir ajan olarak bulunmuştur (25-27). Brentuximab vedotin hem tek ajan olarak hem de standart kemoterapiyle birlikte uygulandığında (BV+ ICE, DHAP ve ESHAP) BV'nin PBSC mobilizasyonunu değiştirmeden veya önemli toksisiteye yol açmadan önemli oranda tam cevap sağladığı, kemoterapi ile kombine verilmesinin olumlu olduğu gösterilmiştir (28-30). Bendamustin-brentuksimab vedotin ile çoklu tedavi $\mathrm{R} / \mathrm{R}$ HL'si olan hastalarda etkin klinik aktiviteye sahiptir. Ve varsa $B V$ 'ye karşı direncin üstesinden gelmeye yardımcı olabilir. Hem BV hem de bendamustin ayakta tedavi olarak uygulanabilir, belirgin hematolojik yan etki ve toksisite göstermezler. İki ajanın bir OKHN öncesi ortamda tek bir ajan ile sağlanan remisyon oran ve hızlarını artırmak amacıyla sinerjistik bir etki oluşturabileceği belirtilmektedir (31-32). Bizim olgu serimizde otolog nakil öncesi 18 hastadan 2 sine BV, 5'ine BV+bendamustin tedavileri verilmiştir. Otolog KHN sonrası nüks saptanan olguların 9'una BV+bendamustin kemoterapi rejimleri ile kombine olarak 
verilmiştir; hastaların hiçbirinde ağır bir toksisite gelişmemiştir. Kaybedilen 2 hasta da kemorezistan hastalardı. Son yıllarda yüksek risk grubu hastalarda (12 aydan erken relaps, kemoterapi direnci, ekstralenfatik organ tutulumu gibi) OKHN sonrası BV ile konsolidasyon tedavisi ile hematolojik toksisiteye yol açmadan daha yüksek hastalıksız sağ kalım sağlanabileceği bildirilmiştir (33-35). Allojenik KHN, OKHN sonrası nüks saptanan veya veya yeterli cevap vermeyen $\mathrm{HL}$ hastaları için bir tedavi opsiyonu olarak düşünülmelidir. Otolog KHN'de olduğu gibi, transplantasyon anındaki hastalık durumu veya diğer bir deyişle kemosensitivitesi, relaps sıklığı ve sağkalım oranları açısından önemlidir. Miyeloablatif kemoterapi rejimleri ile nakil ilişkili mortalitenin yüksek olduğu bildirilmiştir. Düşük yoğunluklu hazırlık rejimleri (RIC) ile relaps dışı mortalitede önemli bir azalma sağlamıştır. Kronik GVHH gelişmesi, azalmış nüks insidansı ve sonuç olarak daha iyi hastalıksız sağ kalım ile sonuçlanmıştır. Düşük yoğunluklu hazırlık rejimler ile benzer sonuçlar veren çalışmalar giderek artmaktadır (36-39).

Nakil sonrası siklofosfamid (PT-Cy) kullanımının ile haploidentik KHN hastalarında GVHD insidansını azalttğı, greft reddini önleyebildiği ve graft versus-lenfoma etkisini azaltmadığı için relaps refrakter $\mathrm{HL}$ hastalarında standart bir prosedür olarak kabul edilmektedir. Bu işlem düşük relaps dışı mortalite oranları (\%4-20) ve atmış 3 yıllık genel sağkalım oranları (\%63), ve düşük nüks oranları (\%21 ila \%31 arasında) ile gelecekte daha çok başvurulacak bir yöntemdir (40-42). Olgu serimizde OKHN sonrası relaps gelişen hastalarda $5^{\prime}$ ine tam uyumlu kardeşten, 3 'üne tam uyumlu akraba dışı vericiden ve 2 'sine de haploidentik nakil yapıldı.

Sonuç olarak AKHN ve özelikle haploidentik nakiller, kolay donör temini, yönetilebilir GVHD, yüksek graft versus lenfoma , düşük toksisite riski olması nedeni ile nüks ve dirençli $\mathrm{HL}$ olguları için önemli bir tedavi seçeneğidir. Ayrıca brentixumab vedotin ve bendamustin AKHN yapılabilmesi için önemli bir köprü tedavi seçeneğidir.

Etik Komite Onayı: Etik komite onayı bu çalışma için İstanbul Medipol Üniversitesi Etik Kurulu'ndan alınmıştır (Sayı: 10840098-604.01.01E.12622).

Bilgilendirilmiş Onam: Katılımcılardan bilgilendirilmiş onam alınmıştır.

Hakem Değerlendirmesi: Dış bağımsız.

Yazar Katkıları: Çalışma Konsepti/Tasarım- Y.Y., M.E., K.Ö., L.T., N.B., V.H., E.T.S.; Veri Toplama- Ş.Ş., S.A.; Veri Analizi/Yorumlama- Y.Y., M.E., L.T., V.H.; Yazı Taslağı- E.T.S., Ş.Ş., S.A.; Son Onay ve Sorumluluk- Y.Y., M.E., K.Ö., L.T., N.B., V.H., E.T.S., Ş.Ş., S.A.

Çıkar Çatışması: Yazarlar çıkar çatışması beyan etmemişlerdir.

Finansal Destek: Yazarlar finansal destek beyan etmemişlerdir.

Ethics Committee Approval: Ethics committee approval was received for this study from the Medipol University Ethics Committee (No: 10840098-604.01.01-E.12622).
Informed Consent: Written consent was obtained from the participants.

Peer Review: Externally peer-reviewed.

Author Contributions: Conception/Design of Study- Y.Y., M.E., K.Ö., L.T., N.B., V.H., E.T.S.; Data Acquisition- Ş.Ş., S.A.; Data Analysis/ Interpretation- Y.Y., M.E., L.T., V.H.; Drafting Manuscript- E.T.S., Ş.Ş., S.A.; Final Approval and Accountability- Y.Y., M.E., K.Ö., L.T., N.B., V.H., E.T.S., Ş.Ş., S.A.

Conflict of Interest: Authors declared no conflict of interest.

Financial Disclosure: Authors declared no financial support.

\section{KAYNAKLAR/REFERENCES}

1. Körholz CM, Metzger ML, Kelly KM, Schwartz CL, Castellanos EM, Dieckmann, et al. Pediatric Hodgkin Lymphoma. J Clin Oncol 2015;33(27):2975-85.

2. Schellong G, Bramswig J, Ludwig R, Gerein V, Jobke A, Jürgens $\mathrm{H}$, et al. Combined treatment strategy in over 200 children with Hodgkin's disease: Graduated chemotherapy, involved field irradiation with low dosage and selective splenectomy-A report of the cooperative therapy study DAL-HD-82 [in German]. Klin Pädiatr 1986;98:137-46.

3. Weiner MA, Leventhal BG, Marcus R, Brecher M, Ternberg J, Behm $F G$, et al. Intensive chemotherapy and low-dose radiotherapy for the treatment of advanced-stage Hodgkin's disease in pediatric patients: A Pediatric Oncology Group study. J Clin Oncol 1991;9:1591-8.

4. Hutchinson RJ, Fryer CJ, Davis PC, Nachman J, Krailo MD, O'Brien $\mathrm{RT}$, et al. MOPP or radiation in addition to ABVD in the treatment of pathologically staged advanced Hodgkin's disease in children: Results of the Children's Cancer Group phase III trial. J Clin Oncol 1998;16:897-906.

5. Schellong G, Potter R, Bramswig J, Wagner W, Prott FG, Dörffel W, et al. High cure rates and reduced long-term toxicity in pediatric Hodgkin's disease: The German-Austrian multicenter trial DALHD-90 The German-Austrian Pediatric Hodgkin's Disease study group. J Clin Oncol 1999;17:3736-44.

6. Donaldson SS, Link MP, Weinstein HJ, Rai SN, Brain S, Billett AL, et al. Final results of a prospective clinical trial with VAMP and lowdose involved-field radiation for children with low-risk Hodgkin's disease. J Clin Oncol 2007;25:332-7.

7. Viviani S, Zinzani PL, Rambaldi A, Brusamolino E, Levis A, Bonfante $V$, et al. ABVD versus BEACOPP for Hodgkin's Lymphoma When High-Dose Salvage Is Planned. N Engl J Med 2011;365(3):203-12.

8. Johnson P, Federico M, Kirkwood A, Fossa A, Berkahn L, Carella A, et al. Adapted Treatment Guided by Interim PET-CT Scan in Advanced Hodgkin's Lymphoma. N Engl J Med 2016;374:2419-29.

9. Lohri A, Barnett M, Fairey RN, O'Reilly SE, Phillips GL, Reece D, et al. Outcome of treatment of first relapse of Hodgkin's disease after primary chemotherapy: identification of risk factors from the British Columbia experience 1970 to 1988 . Blood 1991;77(10):2292-98.

10. Majhail NS, Weisdorf DJ, Defor TE, Miller JS, McGlave PB, Slungaard A, et al. Long-Term Results of Autologous Stem Cell Transplantation for Primary Refractory or Relapsed Hodgkin's Lymphoma. Biol Blood Marrow Transplant 2006;12(10):1065-72. 
11. Satish Shanbhag and Richard Ambinder. Hodgkin Lymphoma: a review and update on recent progress. CA Cancer J Clin 2018;68(2):116-32.

12. Thomson KJ, Peggs KS, Smith P, Cavet J, Hunter A, Pettengell, et al. Superiority of reduced-intensity allogeneic transplantation over conventional treatment for relapse of Hodgkin's lymphoma following autologous stem cell transplantation. Bone marrow transplant 2008;41(9):765-70.

13. Burroughs LM, O'Donnell PV, Sandmaier BM, Storer BE, Luznik L, Symons HJ, et al. Comparison of outcomes of HLA-matched related, unrelated, or HLA-haploidentical related hematopoietic cell transplantation following nonmyeloablative conditioning for relapsed or refractory Hodgkin lymphoma. Biol Blood Marrow Transplant 2008;14(11):1279-87.

14. Thomson KJ, Peggs KS, Smith P, Cavet J, Hunter A, Parker A, et al. Superiority of reduced-intensity allogeneic transplantation over conventional treatment for relapse of Hodgkin's lymphoma following autologous stem cell transplantation. Bone marrow transplant 2008; 41(9):765-70.

15. Porter DL, Stadtmauer EA, Lazarus HM. 'GVHD': graft-versus-host disease or graft-versus-Hodgkin's disease? An old acronym with new meaning. Bone marrow transplant 2003;31(9):739-46.

16. Sureda A, Robinson S, Canals C, Carella AM, Booagerts MA, Caballeros $D$, et al. Reduced-Intensity Conditioning Compared With Conventional Allogeneic Stem-Cell Transplantation in Relapsed or Refractory Hodgkin's Lymphoma: An Analysis From the Lymphoma Working Party of the European Group for Blood and Marrow Transplantation. J Clin Oncol 2008; 26(3):455-62.

17. Burroughs LM, O'Donnell PV, Sandmaier BM, Storer BE, Luznik L, Symons HJ, et al. Comparison of outcomes of HLA-matched related, unrelated, or HLA-haploidentical related hematopoietic cell transplantation following nonmyeloablative conditioning for relapsed or refractory Hodgkin lymphoma. Biol Blood Marrow Transplant 2008;14(11):1279-87.

18. Moskowitz $\mathrm{CH}$, Nimer SD, Zelenetz VAD, et al. A 2-step comprehensive high-dose chemoradiotherapy second-line program for relapsed and refractory Hodgkin disease: analysis by intent to treat and development of a prognostic model. Blood 2001; 97:616-23.

19. Josting A, Rudolph C, Reiser M, Mapara M, Sieber M, Circhner $\mathrm{HH}$, et al. Time intensified dexamethasone-cisplatin-cytarabine: an effective salvage therapy with low toxicity in patients with relapsed and refractory Hodgkin's disease. Ann Oncol 2002;13:1628-35.

20. Baetz T, Belch A, Couban S, Imrie K, Yau J, Myers R, et al. Gemcitabine, dexamethasone and cisplatin is an active and nontoxic chemotherapy regimen in relapsed or refractory Hodgkin's disease: a phase II study by the National Cancer Institute of Canada Clinical Trials Group. Ann Oncol 2003;14:1762-67.

21. Proctor SJ, Jackson GH, Lennard A, Angus B, Wood K, Lucraft HL, et al. Strategic approach to the management of Hodgkin's disease incorporating salvage therapy with highdose ifosfamide, etoposide and epirubicin: a Northern Region Lymphoma Group study (UK). Ann Oncol 2003;14:47-50.

22. Bartlett NL, Niedzwiecki D, Johnson JL, Friedberg JW, Johnson $\mathrm{KB}$, van Besien K, et al. Gemcitabine, vinorelbine, and pegilated liposomal doxorubicin (GVD), a salvage regimen in relapsed Hodgkin's lymphoma: CALGB 59804. Ann Oncol 2007;18:1071-9.
23. Santoro A, Magagnoli M, Spina M, Pinotti G, Siracusano L, Michieli $M$, et al. Ifosfamide, gemcitabine, and vinorelbine: a new induction regimen for refractory and relapsed Hodgkin's lymphoma. Haematological 2007;92:35-41.

24. Labrador J, Cabrero-Calvo M, Perez-Lopez E, Mattheos MV, Vasquez L, Caballero MD, et al. ESHAP as salvage therapy for relapsed or refractory Hodgkin's lymphoma. Ann Hematol 2014;93:1745-53.

25. Moskowitz AJ, Herrera AF, Beawen AW. Relapsed and Refractory Classical Hodgkin Lymphoma: Keeping Pace With Novel Agents and New Options for Salvage Therapy. ASCO educational book 2019;39:476-85.

26. Chen R, Palmer JM, Martin P, Tsai N, Kim Y, Chen BT, et al. Results of a multicenter phase II trial of brentuximab vedotin as second-line therapy before autologous transplantation in relapsed/refractory Hodgkin lymphoma. Biol Blood Marrow Transplant 2015;21:2136-40.

27. Alessandro Broccoli and Pier Luigi Zinzani. The role of transplantation in Hodgkin lymphoma. Br J Haematol 2019;84:93-104.

28. Cassaday RD, Fromm J, Cowan AJ, Libby EN, Philip M, Behnia S, et al. Safety and activity of brentuximab vedotin (BV) plus ifosfanide, carboplatin, and etoposide (ICE) for relapsed/refractory (Rel/Ref) classical Hodgkin lymphoma $(\mathrm{cHL})$ : initial results of a phase I/II study. Blood 2016;128:1834.

29. Garcia-Sanz R, Sureda A, Gonzalez AP, Canales M, Gonzalez $A P$, Pinana JL, et al. Brentuximab vedotin plus ESHAP (BRESHAP) is a highly effective combination for inducing remission in refractory and relapsed Hodgkin lymphoma patients prior to autologous stem cell transplant: a trial of the Spanish Group of Lymphoma and Bone Marrow Transplantation (GELTAMO). Blood 2016;128:1109.

30. Hagenbeek A, Zijlstra JM, Lugtenburg P, Lugtenburg P, Van Imhof G, Nijland M, et al. Transplant BRaVE: combining brentuximab vedotin with DHAP as salvage treatment in relapsed/refractory Hodgkin lymphoma: a hase 1 dose-escalation study. Haematologica 2016;101:44.

31. O'Connor OA, Lue JK, Sawas A, Amengual JE, Deng C, Kalacet M, et al. Brentuximab vedotin plus bendamustine in relapsed or refractory Hodgkin's lymphoma: an international, multicentre, singlearm, phase 1-2 trial. Lancet Oncol 2018;19:257-66.

32. LaCasce AS, Bociek G, Sawas A, Caimi P, Agura E, Matous J, et al. Brentuximab vedotin plus bendamustine: a highly active first salvage regimen for relapsed or refractory Hodgkin lymphoma. Blood 2018;132:40-8.

33. Brice P, Bastion Y, Divine M, Nedellec G, Ferrant A, Gabarre J, et al. Analysis of prognostic factors after the first relapse of Hodgkin's disease in 187 patients. Cancer 1996;78:1293-9.

34. Sureda A, Constans M, Iriondo A, Arranz R, Caballero MD, Vidal MJ, et al. Prognostic factors affecting long-term outcome after stem cell transplantation in Hodgkin's lymphoma autografted after a first relapse. Ann Oncol 2015;16:625-33.

35. Moskowitz CH, Nademanee A, Masszi T, Agura E, Holowiecki J, Abidi $\mathrm{MH}$, et al. Brentuximab vedotin as consolidation therapy after autologous stem-cell transplantation in patients with Hodgkin's lymphoma at risk of relapse or progression (AETHERA): a randomized, double-blind, placebo-controlled, phase 3 trial. Lancet 2015;385:1853-62.

36. Gajevski JL, Phillips GL, Sobocinski KA, Armitage JO, Gale RP, Champlin RE, et al. Bone marrow transplants from HLA-identical siblings in advanced Hodgkin's disease. J Clin Oncol 1996;14: 572-8. 
37. Sureda A, Robinson S, Canals C, Carella AM, Boogaerts MA, Caballero $D$, et al. Reduced-intensity conditioning compared with conventional allogeneic stem-cell transplantation in relapsed or refractory Hodgkin's lymphoma: an analysis from the lymphoma working party of the European group for Blood and Marrow Transplantation. J Clin Oncol 2008;26:455-62.

38. Robinson, SP, Sureda A, Canals C, Russell N, Caballero D, Bacigalupo $A$, et al. Reduced intensity conditioning allogeneic stem cell transplantation for Hodgkin's lymphoma: identification of prognostic factors predicting outcome. Haematologica 2009;94:230-8.

39. Sureda A, Canals C, Arranz R, Caballero D, Ribera JM, Brune M, et al. Allogeneic stem cell transplantation after reduced intensity conditioning in patients with relapsed or refractory Hodgkin's lymphoma. Results of the HDR-ALLO study - a prospective clinical trial by the Grupo Espa nol de Linfomas/Trasplante de Medula Osea (GELTAMO) and the Lymphoma Working Party of the European group for Blood and Marrow Transplantation. Haematologica 2012;97:310-7.
40. Raiola A, Dominietto A, Varaldo R, Ghiso A, Galaverna F, Bramanti $S$, et al. Unmanipulated haploidentical BMT following nonmyeloablative conditioning and post-transplantation $\mathrm{CY}$ for advanced Hodgkin's lymphoma. Bone Marrow Transplant 2014;49:190-4.

41. Castagna L, Bramanti S, Devillier R, Sarina B, Crocchiolo R, Furst $S$, et al. Haploidentical transplantation with post-infusion cyclophosphamide in advanced Hodgkin lymphoma. Bone Marrow Transplant 2017;52:683-8.

42. Abdalla A, Hammad M, Hafez H, Zaghloul MS, Taha H, El-Hennawy $\mathrm{G}$, et al. Outcome predictors of autologous hematopoietic stem cell transplantation in children with relapsed and refractory Hodgkin lymphoma: Single-center experience in a lower- middle-income country. Pediatr Transplant 2019;23:e13531 